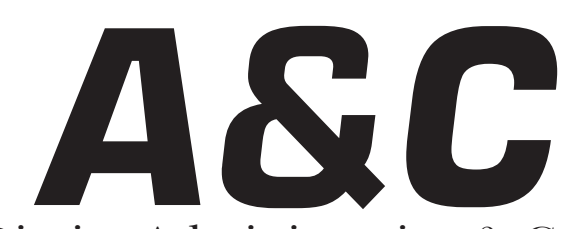

Revista de Direito Administrativo \& Constitucional

Editora Fórum

ISSN 1516-3210

\begin{tabular}{|l|l|l|l|l|l|}
\hline A\&C R. de Dir. Administrativo \& Constitucional & Belo Horizonte & ano 8 & n. 32 & p. 1-256 & abr.jun. 2008 \\
\hline
\end{tabular}




\section{A\&C REVISTA DE DIREITO ADMINISTRATIVO \& CONSTITUCIONAL}

IPDA

Instituto Paranaense

de Direito Administrativo

Direção Geral

Romeu Felipe Bacellar Filho

Direção Editorial

Paulo Roberto Ferreira Motta

Direção Executiva

Emerson Gabardo

Conselho de Redação

Edgar Chiuratto Guimarães

Adriana da Costa Ricardo Schier

Célio Heitor Guimarães

\section{Conselho Editorial}

Jorge Luís Salomoni - in memoriam (Argentina)

José Carlos Abraão (Brasil)

José Eduardo Martins Cardoso (Brasil)

José Luís Said (Argentina)

José Mario Serrate Paz (Uruguai)

Juan Pablo Cajarville Peruffo (Uruguai)

Juarez Freitas (Brasil)

Julio Rodolfo Comadira - in memoriam (Argentina)

Luís Enrique Chase Plate (Paraguai)

Lúcia Valle Figueiredo (Brasil)

Manoel de Oliveira Franco Sobrinho -

in memoriam (Brasil)

in memoriam (Brasil)

Marçal Justen Filho (Brasil)

Marcelo Figueiredo (Brasil)
Márcio Cammarosano (Brasil)
Maria Cristina Cesar de Oliveira (Brasil)

Nelson Figueiredo (Brasil)

Odilon Borges Junior (Brasil)

Pascual Caiella (Argentina)

Paulo Eduardo Garrido Modesto (Brasil)

Paulo Henrique Blasi (Brasil)

Paulo Neves de Carvalho - in memoriam

(Brasil)

Paulo Ricardo Schier (Brasil)

Pedro Paulo de Almeida Dutra (Brasil)

Regina Maria Macedo Nery Ferrari (Brasil)

Rogério Gesta Leal (Brasil)

Rolando Pantoja Bauzá (Chile)

Sérgio Ferraz (Brasil)

Valmir Pontes Filho (Brasil)

Yara Stropa (Brasil)

Weida Zancaner (Brasil)

A246 A\&C Revista de Direito Administrativo \& Constitucional. ano 3, n. 11, jan./mar. 2003. Belo Horizonte: Fórum, 2003.

Trimestral

ano 1, n. 1, 1999 até ano 2, n. 10, 2002 publicada

pela Editora Juruá em Curitiba

ISSN 1516-3210

1. Direito Administrativo. 2. Direito Constitucional.

I. Fórum.

CDD: 342 CDU: 33.342

(C) Editora Fórum Ltda. 2008

Todos os direitos reservados. É proibida a reprodução total ou parcial, de qualquer forma ou por qualquer meio eletrônico ou mecânico, inclusive através de processos xerográficos, de fotocópias ou de gravação, sem permissão por escrito do possuidor dos direitos de cópias (Lei n 9.610, de 19.02.1998).

Editora Fórum Ltda

Av. Afonso Pena, 2770 - 15\%16 andar - Funcionários

CEP 30130-007 - Belo Horizonte/MG - Brasil

Tel.: 08007043737

Internet: www.editoraforum.com.br

e-mail: editoraforum@editoraforum.com.br
Editor responsável: Luís Cláudio Rodrigues Ferreira Coordenação editorial: Olga M. A. Sousa

Pesquisa jurídica: Fátima Ribeiro - OAB/MG 74868

Revisora: Lourdes Nascimento

Projeto gráfico: Luis Alberto Pimenta

Diagramação: Marcelo Belico

Bibliotecária: Fernanda de Paula Moreira -

CRB 2900 - 6a região

Os conceitos e opiniões expressas nos trabalhos assinados são de responsabilidade exclusiva de seus autores.

Impressa no Brasil / Printed in Brazil

Distribuída em todo o Território Nacional 


\title{
A proteção do consumidor como princí- pio da ordem econômica na Constituição de 1988
}

\author{
Ana Claudia Loyola da Rocha \\ Mestranda em Direito Econômico e Social pela PUC/PR. Especialista em Direito Empresarial e em \\ Direito Civil pela PUC/PR. Membro da Comissão de Direito do Consumidor da OAB/PR. Professora \\ de Direito do Consumidor. Advogada.
}

\section{Rodrigo Pironti Aguirre de Castro}

Procurador-Geral do Município de Pinhais - PR. Mestre em Direito Econômico e Social pela PUC/ PR. Especialista em Direito Administrativo pelo Instituto Romeu Bacellar. Especialista em Direito Empresarial pela PUC/PR. Professor do MBA em Gestão Pública OPET. Vice-Presidente do Foro Mundial de Jóvenes Administrativistas (FOMUJAD).

Resumo: Com os preceitos liberais conferidos às contratações ao longo dos séculos XIX e XX e com os princípios do capitalismo reinando sem qualquer sorte de restrição, as contratações tornaram-se desequilibradas, demandando a intervenção do Estado. A tutela dos consumidores, até então exercida pelo Código Civil de 1916, diploma que tinha por premissa o equilíbrio entre as partes contratantes nas relações jurídicas entabuladas, mostrava-se inócua. Por meio da Constituição Federal de 1988, o Estado, portanto, a fim de restabelecer a comutatividade contratual, passou a disciplinar as relações privadas, a infligir a observância da boa-fé contratual, o respeito à dignidade humana e a atenção à função social dos contratos. A proteção do consumidor foi então visualizada pela primeira vez na Constituição Federal de 1988, que a inseriu dentre as garantias fundamentais e a erigiu à categoria de princípio da ordem econômica. Somente, pois, com a promulgação da Constituição Federal, é que foram reconhecidas expressamente a vulnerabilidade do consumidor nas relações de consumo e a premente necessidade de elaboração de um código dedicado especificamente à sua proteção. O Código de Defesa do Consumidor, instituído por expressa determinação constitucional, passou, mediante regras e princípios norteadores, não só a disciplinar as relações de consumo como também a restabelecer o equilíbrio dessa sorte de relação jurídica. Diante do avanço conquistado desde a promulgação da Lei no 8.078/90, é possível dizer que o diploma consumerista está em plena consonância com os objetivos trazidos pela Constituição Federal de 1988 e tem efetivamente realizado os ideais constitucionais de justiça social.

Palavras-chave: Constituição Federal de 1988. Direito econômico e social. Ordem econômica. Atividade econômica. Intervenção do Estado. Direitos e garantias fundamentais. Princípio da defesa do consumidor. Sociedade de consumo. Código de defesa do consumidor. Relações de consumo.

Sumário: 1 Introdução - 2 As transformações do constitucionalismo liberal e seus reflexos na ordem econômica - 3 A intervenção do Estado na atividade econômica e a tutela dos consumidores antes da promulgação da Constituição Federal de 1988 - 4 A defesa do consumidor como garantia fundamental e

A\&C R. de Dir. Administrativo \& Constitucional, Belo Horizonte, ano 8, n. 32, p. 11-29, abr./jun. 2008 
princípio da ordem econômica na Constituição Federal de 1988 - 5 A edição do Código de Defesa do Consumidor - Lei n ${ }^{\circ}$ 8.078/90 - 6 Conclusões

- Referências

\section{Introdução}

O artigo $5^{\circ}$, inciso XXXII, da Constituição Federal de 1988, atribui ao Estado a tarefa de promover a defesa dos consumidores, e o artigo 170, inciso V, da Carta Magna, eleva a defesa do consumidor à categoria de princípio da ordem econômica.

Contudo, inúmeras transformações sociais deram ensejo a esta proteção constitucional do consumidor, bem como à edição da Lei no 8.078/90, destinada especificamente à proteção e à defesa dos consumidores.

Desta forma, com base em pesquisa doutrinária, pretende-se com o presente estudo verificar, primeiramente, que mudanças motivaram a primeira inclusão expressa da defesa do consumidor na Constituição Federal.

Posteriormente, após a análise da intervenção estatal na ordem econômica e do contexto histórico em que essa participação do Estado na economia teve início, passa-se ao estudo da proteção do consumidor anteriormente à promulgação da Constituição Federal de 1988 e à tutela exercida pelo Código Civil de 1916, no item denominado "A intervenção do Estado na atividade econômica e a tutela dos consumidores antes da promulgação da Constituição Federal de 1988”.

Em seguida, com a promulgação da Constituição Federal de 1988, a promoção da defesa do consumidor passa a ser dever do Estado e princípio da ordem econômica. Além disso, cumpre esclarecer que o artigo 48 das Disposições Constitucionais Transitórias determinou a criação, dentro do prazo de cento e vinte dias contados da promulgação da Constituição, de um código de defesa do consumidor pelo Congresso Nacional, razão pela qual mostra-se imprescindível ao presente estudo a análise da defesa do consumidor na Constituição Federal de 1988 em item próprio.

Por fim, analisa-se especificamente a Lei no 8.079/90, que instituiu o Código de Defesa do Consumidor, enquanto norma de ordem pública e interesse social, a relevância deste diploma legal no ordenamento jurídico pátrio e o princípio da vulnerabilidade, verdadeiro alicerce do CDC.

Nas considerações finais será verificada a recepção da proteção do

A\&C R. de Dir. Administrativo \& Constitucional, Belo Horizonte, ano 8, n. 32, p. 11-29, abr./jun. 2008 
consumidor instituída pela Constituição Federal de 1988 pelo Código de Defesa do Consumidor, e os reflexos do sistema de proteção do consumidor brasileiro na ordem econômica.

\section{As transformações do constitucionalismo liberal e seus reflexos na ordem econômica}

A Revolução Industrial criou um marco importante para o estudo do Direito do Consumo, na medida em que se tratou do que se costuma chamar por berço do capitalismo: o início da acumulação do capital, com suporte em preceitos como a plena liberdade contratual e a prevalência da autonomia da vontade, aliado à idéia de que a propriedade privada induz à impossibilidade de intervenção estatal.

Em função da Revolução Industrial, por meio da qual a definição de produção coligou-se ao conceito de massificação, as relações contratuais tiveram que acompanhar os novos rumos reinantes nas sociedades. Luiz Antonio Rizzatto Nunes explica o fenômeno relatado:

Esse modelo de produção industrial, que é o da sociedade capitalista contemporânea, pressupõe planejamento estratégico unilateral do fornecedor, do fabricante, do produtor, do prestador de serviço etc. Ora, esse planejamento unilateral, tinha de vir acompanhado de um modelo contratual. E este acabou por ter as mesmas características da produção. Aliás, já no começo do século $\mathrm{XX}$, o contrato era planejado da mesma forma que a produção.

Não tinha sentido fazer um automóvel, reproduzi-lo vinte mil vezes, e depois fazer vinte mil contratos diferentes para os vinte mil compradores. ${ }^{1}$

Neste modelo tipicamente capitalista, as partes não discutiam o contrato, uma vez que a forma mais comum de contratação tratava-se da contratação em massa, através da qual os preços e todas as demais condições contratuais eram ditados unilateralmente pelos fornecedores de produtos e serviços. Imperava, destarte, a pacta sunt servanda: o contrato fazia lei entre as partes contratantes. A respeito da liberdade de contratação no modelo capitalista, Aline Arquette Leite Novais pondera:

A liberdade de contratar correspondia, necessariamente, a uma ilimitada responsabilidade das partes pelos compromissos assumidos, formando, o contrato, uma relação extremamente forte, podendo ser equiparado à força da própria lei. Nesse sentido, Enzo Roppo anota que: "cada um é absolutamente livre de comprometer-se ou não, mas uma vez que se comprometa fica ligado de modo

${ }^{1}$ Curso de direito do consumidor: com exercícios, p. 4.

A\&C R. de Dir. Administrativo \& Constitucional, Belo Horizonte, ano 8, n. 32, p. 11-29, abr./jun. 2008 
irrevogável à palavra dada: pacta sunt servanda". ${ }^{2}$

A intervenção estatal, portanto, dava-se de forma subsidiária. Em linhas gerais, o Estado, no campo econômico, primava pelo respeito à autonomia dos indivíduos, das famílias, associações de classe e grupos econômicos, somente agindo indiretamente e quando necessário para criar condições favoráveis ao livre exercício da atividade econômica.

Em outras palavras, esta atuação subsidiária do Estado buscava harmonizar as relações entre os indivíduos e as sociedades e criar condições favoráveis ao livre exercício da atividade econômica: o Estado deveria intervir na esfera do domínio econômico tão-somente quando tal intervenção se mostrasse necessária à realização do interesse social, quando buscasse coibir abusos econômicos e preservar a livre concorrência.

No campo do direito positivo, Eros Roberto Grau relata o tratamento conferido pelo legislador constituinte a este período:

As Constituições liberais não necessitavam, no seu nível (delas, Constituições liberais), dispor, explicitamente, normas que compusessem uma ordem econômica constitucional. A ordem econômica existente no mundo do ser não merecia reparos. Assim, bastava o que definido, constitucionalmente, em relação à propriedade privada e à liberdade contratual, ao quanto, não obstante, acrescentava-se umas poucas outras disposições veiculadas ao nível infraconstitucional, confirmadoras do capitalismo concorrencial, para que se tivesse composta a normatividade da ordem econômica liberal. ${ }^{3}$

Todavia, a teoria liberal passou por profundas transformações no final do século XIX, impulsionadas por preocupações ainda centradas na liberdade individual, mas almejando a igualdade de oportunidades. O liberalismo perde seu enfoque minimalista e destaca formas positivas de contribuição do Estado à promoção do bem-estar, imprescindível ao crescimento e desenvolvimento do homem. ${ }^{4}$

Houve, assim, a necessidade de intervenção do Estado à medida que já não se observava, nas contratações, pressupostos como a dignidade da pessoa humana. A pacta sunt servanda passou a ser mitigada pela teoria do rebus sic standibus, que orientava as partes ao cumprimento dos contratos desde que os fatos não houvessem sido alterados. Antônio Carlos Efing explica o momento histórico:

\footnotetext{
${ }^{2}$ A teoria contratual e o Código de defesa do consumidor, p. 59.

${ }^{3}$ A ordem econômica na Constituição de 1988, p. 56.

${ }^{4}$ BORGES. Preâmbulo da Constituição \& a ordem econômica, p. 172.
} 
A igualdade formal no Estado Liberal e capitalista propiciou, somada às diferenças entre classes, a ocorrência de inúmeras desigualdades (substanciais). Além deste fato, o contrato do Estado liberal não prevaleceu sobre as mudanças sociais e principiológicas. A partir disto, observa-se que valores como autonomia da vontade deu lugar a autonomia privada e o contrato passa de apenas instrumento de troca que atendia exclusivamente aos interesses das partes, devendo obedecer a uma finalidade social. Isto é, não mais prevalece, como supremo, o individualismo e sim o interesse comum. ${ }^{5}$

Surge assim a idéia de função social do contrato como forma de permitir a inclusão social. Nesta medida, a função social do contrato legitima a limitação à liberdade de contratar, estabelecendo restrições aos efeitos que o contrato reflete perante terceiros, perante a sociedade, e mesmo em relação às próprias partes, primando pela solidariedade, sempre com o objetivo maior de alcançar a justiça real — abandonando a busca pela justiça formal - e de transformar efetivamente a sociedade brasileira em uma sociedade mais justa e livre.

Não se trata fundamentalmente, como bem observa Eros Roberto Grau, de uma ruptura com o capitalismo, mas de uma adaptação e aprimoramento da atuação estatal no que tange à ordem econômica e que trouxe necessários reflexos legislativos:

A introdução, no nível constitucional, de disposições específicas, atinentes à conformação da ordem econômica (mundo do ser), não consubstancia, em rigor, uma ruptura dela. Antes, pelo contrário, expressa - como venho afirmando - o desígnio de se a aprimorar, tendo-se em vista a sua defesa. A ordem econômica (mundo do dever-ser) capitalista, ainda que se qualifique como intervencionista, está comprometida com a finalidade de preservação do capitalismo. Daí a feição social, que lhe é atribuída, a qual, longe de desnudar-se como mera concessão a um modismo, assume, nitidamente, conteúdo ideológico. ${ }^{6}$

A propriedade privada, a livre concorrência, o livre exercício da atividade econômica, traduzidos no princípio genérico da liberdade de iniciativa, são ideais capitalistas preservados na Constituição Federal de 1988, que abre espaço à intervenção estatal na atividade econômica em casos específicos, que exigem a interferência do Estado, como, por exemplo, nos casos que tenham por objeto relevante interesse coletivo. ${ }^{7}$

Desta forma, portanto, dá-se a modificação do contexto social brasi-

\footnotetext{
${ }^{5}$ Revisão contratual no CDC e no CC. In: CAPAVERDE; CONRADO (Org.). Repensando o direito do consumidor: 15 anos do CDC, p. 56.

${ }^{6}$ A ordem econômica na Constituição de 1988, p. 58.
} 
leiro, que trouxe inevitáveis reflexos à legislação pátria.

\section{A intervenção do Estado na atividade econômica e a tutela dos consumidores antes da promulgação da Constituição Federal de 1988}

Esclarece Eros Roberto Grau que a transformação relatada foi impulsionada pela necessidade de implementação de políticas públicas e que, uma vez positivada a ordem econômica em nosso ordenamento jurídico, mostrou-se fundamental o seu aprimoramento, através da efetiva determinação do modo de produção econômica:

A transformação que refiro se dá no instante em que as precedentes ordens econômicas (mundo do dever-ser) passam a instrumentar a implementação de políticas públicas. Vale dizer: no instante em que a ordem econômica — parcela da ordem jurídica -, já instalada no nível constitucional, passa a predicar o aprimoramento da ordem econômica (mundo do ser), visando à sua preservação. ${ }^{8}$

Paralelamente a essas transformações sociais, econômicas e jurídicas, as relações de consumo, cuja existência evidentemente antecede à promulgação da Constituição Federal de 1988, já recebiam antes desse advento, a tutela de nosso ordenamento jurídico.

Em outras palavras, antes mesmo da promulgação da Constituição Federal de 1988, já se mostrava evidente a necessidade da tutela legal do consumidor, pois contemporaneamente o homem já vivia um novo modelo de associativismo, a sociedade de consumo, e como tal, marcada por um número crescente de produtos e serviços, pelo crédito e pelas novas estratégias de marketing, assim como pela dificuldade de acesso à justiça. ${ }^{9}$

Até o ano de 1990, quando o Código de Defesa do Consumidor entrou em vigor, e mesmo antes de 1988, quando se viu pela primeira vez a defesa do consumidor positivada em um diploma legal, era o Código Civil de 1916 que assumia a proteção das partes envolvidas nas relações de consumo sem, contudo, dar enfoque à parte vulnerável desta sorte de relação jurídica, ou sem distinguir, para fins de proteção legal, consumidores de fornecedores.

No Brasil, as Constituições de 1937, 1946 e 1947, apesar de tratarem

\footnotetext{
7 FERREIRA. Curso de direito constitucional, p. 577.

${ }^{8}$ A ordem econômica na Constituição de 1988, p. 57.

${ }^{9}$ GRINOVER. Código brasileiro de defesa do consumidor: comentado pelos autores do anteprojeto, p. 6.
}

A\&C R. de Dir. Administrativo \& Constitucional, Belo Horizonte, ano 8, n. 32, p. 11-29, abr./jun. 2008 
sobre a ordem econômica, tutelando direitos e proibindo inclusive a usura, não trataram especificamente da tutela do consumidor. Antônio Carlos Efing lembra que:

Como matéria constitucional, as primeiras normas de cunho protetivo à economia popular despontam em 1934. Mais tarde, com o Dec.-lei 869, de 18.11.1938, a usura e o abuso de poder econômico aparecem como crimes contra a economia popular. A Lei 1.521, de 26.12.1951, que trata de crimes contra a economia popular, dirigiu sua tutela ao consumidor. $\mathrm{O}$ art. $2^{\circ}$, em seus diversos incisos, enumera um conjunto de ilícitos tais como: expor à venda ou vender mercadoria ou produto alimentício cujo fabrico haja desatendido a determinações oficiais, quanto ao peso e composição (inc. III); misturar gêneros e mercadorias de espécies diferentes, expô-los à venda e assim fazê-los como puros (inc. V). ${ }^{10}$

Assim, era o Código Civil de 1916 que tutelava as relações de consumo, sem, contudo, visualizar o desequilíbrio que maculava os negócios jurídicos celebrados entre consumidores e fornecedores.

$\mathrm{Na}$ ótica do legislador pátrio, consumidores e fornecedores encontravam-se em pé de igualdade nas contratações, de modo que não se fazia necessária a outorga de qualquer privilégio aos consumidores, da mesma forma como nenhum outro contraente, como se extrai da análise do texto legal, gozava de benefícios na contratação.

Frise-se, por oportuno, que não só as regras, mas também os princípios que orientavam o Código Civil de 1916, não vislumbravam o flagrante desequilíbrio existente entre as partes contratantes das relações firmadas entre consumidores e fornecedores, tendo por objeto a aquisição de produtos ou a prestação de serviços.

Contudo, foram as mudanças econômicas e tecnológicas ${ }^{11}$ que acentuaram a evolução jurídica da proteção do consumidor no Brasil e tornaram perceptível a necessidade de tutela específica do consumidor.

Através de tais mudanças, visualizou-se que a instituição de normas que protegessem os consumidores dos defeitos de produtos e serviços, bem como das diversas irregularidades praticadas indistintamente pelos fornecedores no mercado de consumo, havia se tornado imperativa. Neste sentido, merecem destaque as relevantes observações de Antônio Carlos Efing:

Os mecanismos da distribuição sofrem, na verdade, um impulso da evolução

\footnotetext{
${ }^{10}$ Fundamentos do direito das relações de consumo, p. 22-23.

11 BAPTISTA, Luiz Olavo. Proteção do consumidor: aspectos de direito comparado e internacional. Revista de Direito Mercantil, São Paulo, v. 30, n. 83, p. 19-20, jul./set. 1991.
} 
industrial. A noção de contratos de massa, o uso universal das condições gerais de venda, mesmo as ações no campo do Direito do Trabalho ou para a defesa dos chamados interesses difusos surgem como adaptações dos instrumentos jurídicos, a fim de que possam eles desempenhar o controle das imperfeições da produção e dos métodos de distribuição e comercialização dos produtos e da prestação de serviços. A responsabilidade dos produtores frente à massa dos consumidores torna-se coletiva, cabendo aos primeiros a seguridade de sua produção face aos usuários. Em homenagem ao bem-estar da sociedade e das relações humanas, o legislador consagra a proteção ao consumidor, já que se preocupa com os acidentes advindos do uso de produtos e com problemas decorrentes da prestação de serviços. ${ }^{12}$

Ada Pellegrini Grinover e Antônio Herman de Vasconcellos e Benjamin também explicam a necessidade de tutela legal ao consumidor, não obstante a proteção já exercida pelo Código Civil de 1916, fundamentando-a nas mudanças drásticas verificadas no mercado de consumo com o transcorrer dos séculos, e que tornaram ainda mais severo o desequilíbrio contratual instaurado entre consumidores e fornecedores nas relações contratuais entre eles travadas.

Assim, em que pese a tutela genérica do consumidor já haver sido exercida pelo Código Civil de 1916, somente com a Carta Magna de 1988 é que a defesa do consumidor, passando a ser garantia constitucional e princípio da ordem econômica, tornou-se efetiva e, principalmente, eficaz.

A tutela até então existente, como bem destaca Antônio Carlos Efing, não se mostrava adequada às necessidades dos consumidores:

Mesmo antes da promulgação da Constituição Federal de 1988, o consumidor brasileiro de alguma forma já recebia a tutela legal dos seus direitos. Todavia, o sistema legal anterior à atual Constituição não permitia que essa tutela fosse adequada, já que orientada por princípios, instrumentos e procedimentos inadequados. A inclusão da matéria atinente à proteção do consumidor na Constituição, conforme leciona Norbert Reich, coaduna-se com a função do Estado em intervir em situações de desigualdade e desequilíbrio social que não poderiam ser satisfatoriamente acomodadas ou corrigidas com o uso de instrumentos meramente políticos ou econômicos. ${ }^{13}$

Com a Constituição Federal de 1988, portanto, o legislador constituinte tornou a promoção da proteção do consumidor dever do Estado, enquanto garantia fundamental, e erigiu a defesa do consumidor à categoria de princípio da ordem econômica, determinando a criação de normas

\footnotetext{
12 Fundamentos do direito das relações de consumo, p. 21-22.

13 Fundamentos do direito das relações de consumo, p. 26.

${ }^{14}$ A teoria dos princípios de Ronald Dworkin encontra-se esmiuçada na obra Los derechos en serio.
}

A\&C R. de Dir. Administrativo \& Constitucional, Belo Horizonte, ano 8, n. 32, p. 11-29, abr./jun. 2008 
especificamente destinadas aos consumidores brasileiros.

\section{A defesa do consumidor como garantia fundamental e princípio da ordem econômica na Constituição Federal de 1988}

A Defesa do Consumidor apresenta-se, então, justificada como princípio geral da atividade econômica no artigo 170, inciso V, da Constituição Federal de 1988, segundo o qual:

Art. 170. A ordem econômica, fundada na valorização do trabalho humano e na livre iniciativa, tem por fim assegurar a todos existência digna, conforme os ditames da justiça social, observados os seguintes princípios: (...)

$\mathrm{V}$ - defesa do consumidor.

Primeiramente, e para que se possa compreender por que a defesa do consumidor trata-se de princípio da ordem econômica, e não de regra, e qual o real alcance desta sorte de norma, cumpre mencionar os fundamentos jurídicos da teoria dos princípios defendida por Ronald Dworkin. ${ }^{14}$

$\mathrm{O}$ autor distingue regras de princípios, asseverando que ambos se tratam de normas jurídicas. Em outras palavras, das normas jurídicas é que decorreriam as regras e os princípios.

As regras seriam normas que exigem um cumprimento pleno, de sorte que, se uma regra é válida, seu cumprimento é obrigatório, fazendo-se necessário observar precisamente o que se ordena, nem mais nem menos. A incidência das regras, desta forma, estaria restrita, limitada ao caso concreto e específico para o qual a regra foi formulada. Ou, como assevera Dworkin, as regras disciplinariam uma determinada situação. Em se verificando a ocorrência desta determinada situação, as regras serão aplicadas; caso contrário, não. Como mencionado, a incidência das regras teria cabimento somente em casos concretos. ${ }^{15}$

Os princípios, porém, estariam compreendidos no conjunto de padrões que, na sua terminologia, referem-se a certas circunstâncias que, sem serem normas, servem para elucidar direitos e deveres. Assim, os princípios teriam um campo de incidência muito maior, pois atenderiam a uma multiplicidade de situações e, justamente por tal razão, estariam aptos a sanar quaisquer situações para as quais, à primeira vista, não se possa

15 DWORKIN. Los derechos en serio, p. 163-171.

${ }^{16}$ DWORKIN. Los derechos en serio, p. 213.

A\&C R. de Dir. Administrativo \& Constitucional, Belo Horizonte, ano 8, n. 32, p. 11-29, abr./jun. 2008 
visualizar uma solução jurídica. ${ }^{16}$

Além disso, os princípios representariam os objetivos sociais e o ideal de integridade do direito de determinada sociedade. ${ }^{17}$

Gisele Cittadino também esclarece a exata distinção conferida por Dworkin entre regras, aqui denominadas normas, e princípios:

Dworkin assinala que normas e princípios possuem estatutos lógico-argumentativos distintos, pois enquanto as normas definem as suas condições de aplicação, os enunciados dos princípios jurídicos necessitam de interpretação, de vez que não são capazes de determinar suas condições de aplicação. ${ }^{18}$

A respeito da relevância dos princípios no ordenamento jurídico brasileiro, oportuno o comentário do doutrinador Paulo Bonavides, que ressalta a importância desta sorte de norma nas Constituições contemporâneas e nos precedentes firmados pelos tribunais pátrios:

A esta altura, os princípios se medem normativamente, ou seja, têm alcance de norma e se traduzem por uma dimensão valorativa, maior ou menor, que a doutrina reconhece e a experiência consagra. Consagração observada de perto na positividade dos textos constitucionais, donde passam à esfera decisória dos arestos, até constituírem com estes aquela jurisprudência principal, a que se reporta, com toda a argúcia, García de Enterría.

(...)

A importância vital que os princípios assumem para os ordenamentos jurídicos se torna cada vez mais evidente, sobretudo se lhes examinarmos a função e presença no corpo das Constituições contemporâneas, onde aparecem como os pontos axiológicos de mais alto destaque e prestígio com que fundamentar na Hermenêutica dos tribunais a legitimidade dos preceitos da ordem constitucional. ${ }^{19}$

Pelo exposto, a defesa do consumidor, enquanto princípio da ordem econômica, tem aplicação ampla, devendo nortear a atividade econômica e sobrepor-se aos interesses puramente mercantis. Aliás, como observa Alexandre Walmott Borges, “a Ordem Econômica da Constituição de 1988 consagra um modelo de Estado Social, com ações na economia em busca de bem-estar social, deixando em aberto, ao espaço infraconstitucional, as definições explícitas dessa política econômica de bem-estar". ${ }^{20}$

Veja-se ainda que, além de princípio da ordem econômica, a defesa dos consumidores trata-se também de direito fundamental, nos termos

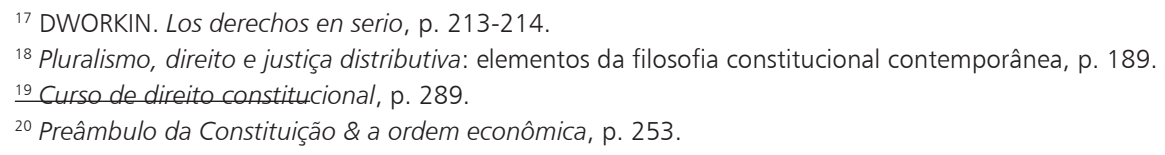

A\&C R. de Dir. Administrativo \& Constitucional, Belo Horizonte, ano 8, n. 32, p. 11-29, abr./jun. 2008 
do artigo 5 ${ }^{\circ}$, inciso XXXII da Constituição Federal de 1988 que, quando dispõe sobre os Direitos e Garantias Fundamentais, estabelece:

Art. $5^{\circ}$ Todos são iguais perante a lei, sem distinção de qualquer natureza, garantindo-se aos brasileiros e aos estrangeiros residentes no País a inviolabilidade do direito à vida, à liberdade, à igualdade, à segurança e à propriedade, nos termos seguintes:

(...)

XXXII - o Estado promoverá, na forma da lei, a defesa do consumidor.

Da conjugação dos dispositivos constitucionais acerca da proteção e defesa dos consumidores, extrai-se a plena legitimidade de que passam a gozar todas as medidas de intervenção estatal necessárias a assegurar a proteção instituída pelo legislador constituinte. ${ }^{21}$

Isto porque a defesa do consumidor, como deixa claro a redação do artigo $5^{\circ}$, inciso XXXII da Constituição Federal de 1988, dependerá da participação do Estado para que possa tornar-se efetiva. Não há como, frise-se, implementar a defesa do consumidor como princípio constitucional e assegurar a sua observância sem a intervenção estatal, tornando eficazes e eficientes todas as suas diretrizes.

A respeito da necessidade de intervenção do Estado para a concretização da defesa do consumidor, Eros Roberto Grau destaca o caráter conformador da ordem econômica deste princípio e assevera:

O caráter constitucional conformador da ordem econômica, deste como dos demais princípios de que tenho cogitado, é inquestionável. Três aspectos devem, no entanto, ser neste passo considerados.

(...)

O terceiro aspecto a referir respeita à não configuração das medidas voltadas à defesa do consumidor como meras expressões da ordem pública. A sua promoção há de ser lograda mediante a implementação de específica normatividade e de medidas dotadas de caráter interventivo. Por isso mesmo é que o caráter eminentemente conformador da ordem econômica, do princípio, é nítido. ${ }^{22}$

Imprescindível, portanto, a presença do Estado para assegurar a proteção e a defesa do consumidor. Por tal razão, o legislador constituinte determinou no Ato das Disposições Constitucionais Transitórias (ADCT), artigo 48 da Carta Magna, que: "O Congresso Nacional, dentro de cento e vinte dias da promulgação da Constituição, elaborará código de defesa 21 SILVA. Curso de direito constitucional positivo, p. 263.

22 A ordem econômica na Constituição de 1988, p. 273-274.

${ }^{23}$ GRINOVER et al. Código brasileiro de defesa do consumidor: comentado pelos autores do anteprojeto, p. 6. 
do consumidor".

A justificativa para a redação do referido dispositivo constitucional é prestada por Ada Pellegrini Grinover e Antônio Herman de Vasconcellos e Benjamin, para quem:

De fato, a Constituição, ao cuidar dos Direitos e Garantias Fundamentais, estabelece, no inc. XXXII do artigo $5^{\circ}$, que "o Estado promoverá, na forma de lei, a defesa do consumidor". O legislador maior, entretanto, entendeu que tal não bastava. Assim, mais adiante, no art. 48 do Ato das Disposições Constitucionais Transitórias, determina que o "Congresso Nacional, dentro de cento e vinte dias da promulgação da Constituição". ${ }^{23}$

As Disposições Constitucionais Transitórias, como se pode facilmente concluir, são temporárias, na medida em que, uma vez materializada a finalidade por elas perseguida, tais normas desaparecem. Este desaparecimento, objetivamente, é ocasionado pelo esgotamento do prazo fixado para o cumprimento das determinações ou dos atos nelas estabelecidos, pela sucumbência do direito no tempo ou pelo alcance da garantia ou da situação assegurada aos respectivos titulares. ${ }^{24}$

\section{A edição do Código de Defesa do Consumidor - Lei n 8.078/90}

Não obstante ter determinado a Constituição Federal de 1988 que, dentro de prazo de 120 (cento e vinte) dias contados de sua promulgação, haveria o Congresso Nacional que editar um Código de proteção e defesa dos consumidores, antes mesmo da promulgação da Carta Magna, já havia sido constituída uma comissão no âmbito do Conselho Nacional de Defesa do Consumidor, com o objetivo de apresentar Anteprojeto do Código de Defesa do Consumidor. ${ }^{25}$

Assim, após os trabalhos sucessivos da comissão e superada toda a tramitação legislativa, em 11 de setembro de 1990 foi promulgada a Lei no 8.078/90, denominada Código de Defesa do Consumidor, que veio a dispor sobre a proteção do consumidor.

A importância do Código de Defesa do Consumidor é refletida na evolução do tratamento jurídico destinado às pessoas, consubstanciado na busca pela igualdade material dos indivíduos que compõem uma relação

\footnotetext{
${ }^{24}$ HORTA. Estudos de direito constitucional, p. 327.

25 GRINOVER et al. Código brasileiro de defesa do consumidor: comentado pelos autores do anteprojeto, p. 1.

${ }^{26}$ DONATO. Proteção do consumidor: conceito e extensão, p. 21.
}

A\&C R. de Dir. Administrativo \& Constitucional, Belo Horizonte, ano 8, n. 32, p. 11-29, abr./jun. 2008 
jurídica de consumo. Maria Antonieta Zanardo Donato destaca a verdadeira revolução de que se tratou a promulgação do Código de Defesa do Consumidor: "Com a codificação promulgada em 1990, conferiu-se ao direito do consumidor a sua autonomia, e, simultaneamente, promoveu-se uma reformulação evolutiva no direito positivo, ao serem resgatadas as pessoas e suas funções do processo econômico para a ordem jurídica" ${ }^{26}$

Antônio Carlos Efing, no mesmo sentido, observa que a Lei ${ }^{\circ}$ 8.078, de 11.09.1990 (Código de Defesa do Consumidor) "Pode ser considerada como o divisor de águas para a sociedade brasileira em geral, entre os problemas decorrentes da evolução industrial irrefreada e conseqüente massificação do consumo, e a possibilidade de solução dos mesmos". ${ }^{27}$

Desta forma, diante de toda base constitucional já oportunamente analisada, o artigo $1^{\circ}$ do Código de Defesa do Consumidor veio dispor que: "O presente Código estabelece normas de proteção e defesa do consumidor, de ordem pública e interesse social, nos termos dos arts. $5^{\circ}$, inciso XXXII, 170, inciso V, da Constituição Federal e art. 48 de suas Disposições Transitórias".

Importante mencionar que a defesa do consumidor trata de interesses coletivos, fundamentando-se em normas de natureza cogente, que não podem ser derrogadas pelas partes, como bem ressalta Antônio Carlos Efing:

Quando o CDC preceitua o estabelecimento de normas de ordem pública e interesse social para reger as relações de consumo, quer o legislador proporcionar o equilíbrio dentro do qual o consumidor possa se equiparar ao fornecedor, sem que este último se valha de sua vontade para obter vantagens mediante a imposição de seus interesses. Portanto, o CDC, ao prever normas impositivas de natureza cogente, ordem pública e interesse social, sobrepõe-se à vontade das partes, no intuito de promover a defesa do consumidor, não cabendo às partes da relação de consumo a derrogação de tais preceitos cogentes contidos no CDC. ${ }^{28}$

Em que pese ser o Código de Defesa do Consumidor um direito assegurado pela Constituição, é imprescindível entender a relevância de ser uma norma de interesse social, como bem colocado por Cláudia Lima Marques:

O Código de Defesa do Consumidor constitui verdadeiramente uma lei de fun-

27 Fundamentos do direito das relações de consumo, p. 31.

28 Fundamentos do direito das relações de consumo, p. 34.

${ }^{29}$ Comentários ao código de defesa do consumidor: art. $1^{\circ}$ a 74 : aspectos materiais, p. 55.

A\&C R. de Dir. Administrativo \& Constitucional, Belo Horizonte, ano 8, n. 32, p. 11-29, abr./jun. 2008 
ção social, lei de ordem pública econômica, de origem claramente constitucional. A entrada em vigor de uma lei de função social traz como conseqüência modificações profundas nas relações juridicamente relevantes na sociedade..$^{29}$

Para melhor entender a amplitude em que está inserida a proteção do consumidor, José Geraldo Brito Filomeno faz uma breve análise sobre as relações contratuais contemporâneas:

Situados nessa perspectiva, tudo hoje em dia é direito do consumidor: o direito à saúde e à segurança; o direito de defender-se contra a publicidade enganosa e mentirosa; o direito de informação sobre os produtos, os serviços e suas características, sobre o conteúdo dos contratos e a respeito dos meios de proteção e defesa; o direito à liberdade de escolha e à igualdade na contratação; o direito de intervir na fixação do conteúdo do contrato, o direito de não se submeter às cláusulas abusivas; o direito de reclamar judicialmente pelo descumprimento ou cumprimento parcial ou defeituoso dos contratos; o direito à indenização pelos danos e prejuízos sofridos; o direito de associar-se para a proteção dos seus interesses; o direito de voz e representação em todos os organismos cujas decisões afetem diretamente seus interesses; o direito, enfim, como usuários, a uma eficaz prestação de serviços públicos e até mesmo à proteção do meio ambiente. ${ }^{30}$

O princípio da igualdade, disposto também no artigo $3^{\circ}$ da Constituição Federal, ${ }^{31}$ traz a idéia do tratamento igualitário destinado às pessoas, idealizado pelo legislador constituinte. No Direito do Consumo, vê-se a efetividade deste princípio instrumentalizada através de outro princípio: o princípio da vulnerabilidade do consumidor. José Geraldo Brito Filomeno trata da igualdade abordada na Constituição Federal de 1988 e do princípio da vulnerabilidade, alicerce do Código de Defesa do Consumidor, nos seguintes termos:

Como já afirmava o celebre Ruy Barbosa, a democracia não é exatamente o regime político que se caracteriza pela plena igualdade de todos perante a lei, mas sim pelo tratamento desigual dos desiguais.

No âmbito da tutela especial do consumidor, efetivamente, é ele sem dúvida a parte mais fraca, vulnerável, se se tiver em conta que os detentores dos meios de produção é que detêm todo o controle do mercado, ou seja, sobre o que produzir, como produzir e para quem produzir. ${ }^{32}$

\footnotetext{
${ }^{30}$ Código brasileiro de defesa do consumidor: comentado pelos autores do anteprojeto, p. 118-119.

${ }^{31}$ Art. $3^{\circ}$ Constituem objetivos fundamentais da República Federativa do Brasil: I - construir uma sociedade livre, justa e solidária; II - garantir o desenvolvimento nacional; III - erradicar a pobreza e a marginalização e reduzir as desigualdades sociais e regionais; IV - promover o bem de todos, sem preconceitos de origem, raça, sexo, cor, idade e quaisquer outras formas de discriminação.

${ }^{32}$ Código brasileiro de defesa do consumidor: comentado pelos autores do anteprojeto, p. 55.
} 
Esclarecendo os pressupostos que fundamentam o princípio da vulnerabilidade, cumpre esclarecer que, independentemente do nível social, cultural ou econômico de cada consumidor, é claro que todos dependem de maneira incontroversa da diária aquisição de produtos e contratação regular de serviços para que possam sobreviver. E não é dado ao consumidor optar por outros produtos ou serviços, senão os que lhe são ofertados no mercado de consumo pelos fornecedores. Aí reside a vulnerabilidade do consumidor, na medida em que se sujeita e se submete - não por opção, mas por absoluta falta de alternativas - ao poderio dos fornecedores.

Neste sentido, observa-se que o consumidor, sem dúvida alguma, é a parte mais frágil da relação de consumo. Isto porque não lhe é característica a disposição de elementos que lhe possibilitem o controle do mercado, estando este verdadeiramente a exclusivo talante do fornecedor. Se não pode o consumidor prover suas necessidades, resta claro o vínculo de dependência que mantém com os fornecedores que atuam no mercado de consumo.

Esta submissão é a responsável pela fundamentação do princípio da vulnerabilidade que, partindo do pressuposto de que o consumidor depende dos empresários, fornecedores pessoas físicas ou entes despersonalizados para a manifestação de sua vontade, conclui ser o consumidor imprescindivelmente a parte mais frágil da relação de consumo. ${ }^{33}$

Destarte, por serem todos os consumidores, mesmo que em maior ou menor grau, dependentes dos fornecedores de produtos e serviços, é que a vulnerabilidade torna-se, com a edição do Código de Defesa do Consumidor, presumida. Cláudia Lima Marques, Antônio Herman de Vasconcellos e Benjamin e Bruno Miragem atestam: "Defendemos que, em face do art. $2^{\circ}$ do CDC e do art. $4^{\circ}$, I, desta lei especial, milita uma presunção de vulnerabilidade para as pessoas físicas destinatárias finais do serviço" ${ }^{34}$

Assim, somente partindo-se do pressuposto de que o consumidor, por depender diretamente do fornecedor, é vulnerável, e conseqüentemente a parte mais frágil da relação de consumo, é que se pode restabelecer o equilíbrio desta relação jurídica. E como assinala Luiz Antonio Rizzatto Nunes, "Tal reconhecimento é uma primeira medida de realização da iso-

33 EFING. Fundamentos do direito das relações de consumo, p. 105.

${ }^{34}$ Comentários ao código de defesa do consumidor: art. $1^{\circ}$ a 74: aspectos materiais, p. 121.

A\&C R. de Dir. Administrativo \& Constitucional, Belo Horizonte, ano 8, n. 32, p. 11-29, abr./jun. 2008 
nomia garantida na Constituição Federal". ${ }^{35}$

O que busca, portanto, o Código de Defesa do Consumidor, elaborado por determinação do legislador constituinte, é dar tratamento diferenciado ao consumidor, garantindo a ele que os direitos que lhe foram constitucionalmente assegurados sejam materialmente efetivados.

\section{Conclusões}

Com as mudanças sociais verificadas ao longo da existência do Estado Liberal, e com os princípios do capitalismo reinando sem qualquer sorte de restrição, as contratações tornaram-se desequilibradas. As Constituições, por sua vez, limitadas a dispositivos que aludiam somente à liberdade contratual e à propriedade privada, acabaram por tornar imperativa a intervenção do Estado.

A tutela dos consumidores, neste contexto, não era tratada adequadamente pela legislação vigente à época. O Código Civil de 1916, principal diploma a exercer a defesa do consumidor, tinha por premissa $\mathrm{o}$ equilíbrio entre as partes contratantes nas relações jurídicas entabuladas, e conseqüentemente deixava o consumidor desamparado. A legislação esparsa, por sua vez, ainda não havia tratado expressamente da defesa do consumidor em qualquer dispositivo.

Desta forma, a proteção do consumidor é visualizada pela primeira vez na Constituição Federal de 1988, que a inseriu dentre as garantias fundamentais, impondo ao Estado a tarefa de promovê-la. Além da referida previsão, a defesa do consumidor é também promovida à categoria de princípio da ordem econômica, o que garante sua ampla incidência e a propagação de seus reflexos por todo o ordenamento jurídico.

Através da Constituição Federal de 1988, o Estado, portanto, a fim de restabelecer a comutatividade contratual, passa a disciplinar as relações privadas, a infligir a observância da boa-fé contratual, o respeito à dignidade humana e a atenção à função social do contrato. Tem-se uma nova forma de percepção do direito, que outrora privilegiava a propriedade em detrimento do ser humano.

Destarte, somente com a promulgação da Constituição Federal de

${ }^{35}$ Comentários ao código de defesa do consumidor: direito material (arts. $1^{\circ}$ a 54), p. 106.

A\&C R. de Dir. Administrativo \& Constitucional, Belo Horizonte, ano 8, n. 32, p. 11-29, abr./jun. 2008 
1988 é que se reconhece expressamente o consumidor como parte vulnerável das relações de consumo, razão pela qual determinou o legislador constituinte a elaboração, pelo Congresso Nacional, de um código dedicado especificamente à proteção e defesa dos consumidores.

Uma vez editado o Código de Defesa do Consumidor (Lei $\mathrm{n}^{\circ}$ 8.078/90), os consumidores passaram a ter tratamento diferenciado, através de regras e princípios particularmente destinados à sua proteção, visando ao equilíbrio dos negócios jurídicos firmados com fornecedores, tendo por objeto a aquisição de produtos e a prestação de serviços.

Através da promulgação da Lei no 8.078/90, o Estado, portanto, disciplinou as relações de consumo, protegendo os consumidores dos efeitos nocivos do capitalismo desenfreado e do poderio dos fornecedores, até então dominantes do mercado de consumo.

Conclui-se, desta feita, que, diante de todo o avanço conquistado desde a promulgação da Lei no 8.078/90, o diploma consumerista está em plena consonância com os objetivos trazidos pela Carta Magna de 1988, e tem efetivamente realizado os ideais constitucionais de justiça social e resgate da dignidade humana.

\begin{abstract}
Contract operations became unbalanced by virtue of the liberal ideals coined to them and with capitalism principles ruling over contracts and agreements without any kind of restriction whatsoever. This state of affairs demanded intervention on the part of the State. The legal protection provided to consumers had been settled until then by the Brazilian Civil Code issued in 1916 - an Act that considered the balance between contracting parts - and proved to be innocuous. The State, through the Federal Constitution of 1988, started to govern private relations, imposing the compliance with good-faith principles in contracts, respect to human dignity and care with the social function of contracts and agreements, in order to re-establish contractual fair exchange and equilibrium. So, the consumer's protection was first envisioned in the Federal Constitution of 1988, which inserted such protection among the fundamental guarantees and raised it to the class of economic order principle. Thus, it was only after the promulgation of the Federal Constitution that the consumer's vulnerability in consumption relations and the pressing need to prepare a code specifically designed for the consumer's protection were expressly acknowledged. The Brazilian Consumer Protection Code, issued by virtue of express constitutional order, started — by means of rules and guiding principles - not only to govern consumption relations but to re-establish the balance in this kind of legal relations. Given the progress achieved since Law 8078/90 has been promulgated, it can be said that the consumerist law is in full compliance with the purposes brought by the Federal Constitution of 1988. Furthermore, it has fulfilled
\end{abstract}


the constitutional ideals of social justice.

Keywords: Federal Constitution of 1988. Economic and Social Law. Economic Order. Economic Activity. State Intervention. Fundamental Rights and Warranties. Consumer's Protection Principle. Consumption Society. Consumer Protection Code. Consumption Relations.

\section{Referências}

BASTOS, Celso Ribeiro; MARTINS, Ives Gandra. Comentários à Constituição do Brasil: promulgada em 5 de outubro de 1988. São Paulo: Saraiva, 1988-1989.

BONAVIDES, Paulo. Curso de direito constitucional. 13. ed. São Paulo: Malheiros, 2003.

BORGES, Alexandre Walmott. Preâmbulo da Constituição E̊ a ordem econômica. Curitiba: Juruá, 2003.

CITTADINO, Gisele. Pluralismo, direito e justiça distributiva: elementos da filosofia constitucional contemporânea. 2. ed. Rio de Janeiro: Lumen Juris, 2000.

DI RUFFIA, Paolo Biscaretti. Direito constitucional: instituições de direito público. São Paulo: Revista dos Tribunais, 1984.

DONATO, Maria Antonieta Zanardo. Proteção do consumidor: conceito e extensão. São Paulo: Revista dos Tribunais, 1993.

DWORKIN, Ronald. Los derechos en serio. Barcelona: Biblioteca Selecta, 2004.

DWORKIN, Ronald. O império do direito. São Paulo: Martins Fontes, 2003.

EFING, Antônio Carlos. Fundamentos do direito das relações de consumo. Curitiba: Juruá, 2003.

EFING, Antônio Carlos. Revisão contratual no CDC e no CC. In: CAPAVERDE, Aldaci do Carmo; CONRADO, Marcelo (Org.). Repensando o direito do consumidor: 15 anos do CDC. Curitiba: Ordem dos Advogados do Brasil, Seção do Paraná, 2005.

FERREIRA, Pinto. Comentários à Constituição brasileira. São Paulo: Saraiva, 1994.

FERREIRA, Pinto. Curso de direito constitucional. 5. ed. ampl. e atual. São Paulo: Saraiva, 1991.

FILOMENO, José Geraldo Brito. Código brasileiro de defesa do consumidor: comentado pelos autores do anteprojeto. 6. ed. rev., atual. e ampl. Rio de Janeiro: Forense Universitária, 1999.

FOLMANN, Melissa. Interpretação constitucional principiológica e sigilo bancário. Curitiba: Juruá, 2003.

GRAU, Eros Roberto. A ordem econômica na constituição de 1988. 6. ed. rev. e atual. São Paulo: Malheiros, 2001.

GRINOVER, Ada Pellegrini et al. Código brasileiro de defesa do consumidor: comentado pelos autores do anteprojeto. 6. ed. rev., atual. e ampl. Rio de Janeiro: Forense Universitária, 1999.

HORTA, Raul Machado. Estudos de direito constitucional. Belo Horizonte: Del Rey, 1995.

MARQUES, Cláudia Lima; BENJAMIN, Antônio Herman V.; MIRAGEM, Bruno. Comentários ao Código de defesa do consumidor: arts. $1^{\circ}$ a 74: aspectos materiais. São Paulo: Revista dos Tribunais, 2003.

MARQUES, Cláudia Lima. Comentários ao Código de defesa do consumidor: art. $1^{\circ}$ a 74: aspectos

A\&C R. de Dir. Administrativo \& Constitucional, Belo Horizonte, ano 8, n. 32, p. 11-29, abr./jun. 2008 
materiais. São Paulo: Revista dos Tribunais, 2003.

NOVAIS, Alinne Arquette Leite. A teoria contratual e o Código de defesa do consumidor. São Paulo: Revista dos Tribunais, 2001.

NUNES, Luiz Antonio Rizzatto. Comentários ao Código de defesa do consumidor: direito material (arts. $1^{\circ}$ a 54). São Paulo: Saraiva, 2000.

NUNES, Luiz Antonio Rizzatto. Curso de direito do consumidor: com exercícios. São Paulo: Saraiva, 2004.

SILVA, José Afonso da. Curso de direito constitucional positivo. 24. ed. rev. e atual. nos termos da Reforma Constitucional (até a Emenda Constitucional n. 45, de 8.12.2004, publicada em 31.12.2004). São Paulo: Malheiros, 2005.

Informação bibliográfica deste texto, conforme a NBR 6023:2002 da Associação Brasileira de Normas Técnicas (ABNT):

ROCHA, Ana Claudia Loyola da; CASTRO, Rodrigo Pironti Aguirre de. A proteção do consumidor como princípio da ordem econômica na Constituição de 1988. A\&C Revista de Direito Administrativo \& Constitucional, Belo Horizonte, ano 8, n. 32, p. 11-29, abr./ jun. 2008. 